\title{
Determinants of Neonatal Hypothermia Among Babies Born in Public Hospitals of West Shewa Zone of Oromia Regional State, Ethiopia: Unmatched Case-Control Study
}

This article was published in the following Dove Press journal:

Research and Reports in Neonatology

\author{
Benyam Seifu (D) \\ Daniel Belema \\ Kassa Mamo (D) \\ Gizachew Abdissa Bulto \\ Department of Midwifery, College of \\ Medicine and Health Sciences, Ambo \\ University, Ambo, Ethiopia
}

\begin{abstract}
Background: Neonatal hypothermia is one of the contributors to neonatal morbidity and mortality in Ethiopia. Even though the Oromia regional state is one of the regions with the highest neonatal-mortality rate in Ethiopia, only limited progress has been made towards understanding the determinant factors the causes of mortality such as neonatal hypothermia. Purpose: The study aims to identify determinants of hypothermia among newborns born in public health institutions.

Methods: A hospital-based unmatched case-control study design was employed with a total of 226 (113 cases and 113 controls) babies born in public health facilities West Shewa Oromia region, 2019. The study participants were selected using systematic random sampling. Cases were babies with a temperature $<36.5^{\circ} \mathrm{C}$ and controls were babies with temperature $\geq 36.5^{\circ} \mathrm{C}$ measured at the axilla site using a digital thermometer at the first hour after delivery. The data were collected by interview and checklist using the CS-Entry and exported to SPSS version-23 for analysis. The data were collected from both the babies and their mothers. Binary and multiple logistic regressions were conducted to identify the determinants of hypothermia.
\end{abstract}

Results: A total of 226 babies are participating in the study. Neonates who had not started early breastfeeding $[\mathrm{AOR}=2.2,95 \% \mathrm{CI}(1.3,4.1)]$, who had not skin-to-skin contact $[\mathrm{AOR}=$ $2.8,95 \% \mathrm{CI}(1.3,6.6)]$ and babies with birth weight less than $2500 \mathrm{~g}$ [AOR=2.6, 95\% CI $(1.3,5.2)]$ are found to be at higher risk of hypothermia.

Conclusion and Recommendation: This study has found out that low birth weight babies and those who do not initiate breastfeeding and skin-to-skin contact at higher risk of hypothermia. These risk factors are previously identified by different studies; therefore, birth attendants should give due emphases to the immediate newborn cares in order to prevent neonatal hypothermia.

Keywords: hypothermia, neonates, determinants, Ethiopia

\section{Background}

The proposed Sustainable Development Goals (SDG) target for child mortality aims to end, by 2030, preventable deaths of newborns and children under 5 years of age, with all countries aiming to reduce neonatal mortality to at least as low as 12 deaths per 1000 live births. ${ }^{1}$ But, in 2019 alone, globally estimated 4.01 million children died, mostly from preventable causes. About half of global child mortality is shared
Correspondence: Benyam Seifu

Tel +25191045II84

Email benyamseifu77@gmail.com

Research and Reports in Neonatology 202I:I I |3-2I 
by Sub-Saharan Africa countries, while only 23,551 deaths in North America, 33,517 deaths in Europe and 96,426 deaths are reported from Asian countries. ${ }^{2}$ Newborn deaths account for $45 \%$ of under-five deaths. ${ }^{3}$ Hypothermia among newborns is considered an important contributor to neonatal morbidity and mortality in lowresource settings. ${ }^{4}$

Maintaining a normal body temperature is a critical function of newborn survival. An abnormally low temperature (hypothermia) in neonates occurs when the temperature drops below $36.5^{\circ} \mathrm{C} .^{5}$ Newborns undergo environmental interferences during their adaptation to the extra-uterine life, due to their systemic immaturity. The loss of heat in newborns takes place fast as it can decrease from $2^{\circ} \mathrm{C}$ to $3^{\circ} \mathrm{C}$ in the first half-hour of life, since heat production is not greater than the heat lost by convection, evaporation, and radiation, newborns are at risk of hypothermia. ${ }^{3,5}$ Although hypothermia is rarely a direct cause of death, it contributes to neonatal mortality, mostly as a comorbidity of severe neonatal infections, preterm birth, and asphyxia., ${ }^{4-6}$ Cold stress effects oxygenation by increasing pulmonary artery resistance and reducing surfactant production. Poor perfusion causes an increase in anaerobic metabolism causing worsening acidosis. There is extra utilization of glucose because of the increased metabolism, which can lead to hypoglycemia. ${ }^{3,5}$

In Ethiopia the prevalence of hypothermia is high and it ranges from $50.0 \%$ to $70.0 \%{ }^{9-13}$ Factors associated with hypothermia were various according to different studies from abroad and Ethiopia. Newborn factors like birth weight, ${ }^{14,15}$ pre-term, ${ }^{16}$ breastfeeding initiation, low Appearance, Pulse, Grimace, Activity, and Respiration (APGAR) score, multiple pregnancy, ${ }^{17}$ neonatal abnormality, skin-to-skin contact and bathing within $24 \mathrm{hrs} .{ }^{18}$ Behavioral factors like inappropriate thermal resuscitation appliance and clothing, ${ }^{6,19}$ no wearing cap and no warm intra-facility transportation ${ }^{10}$ are among the commonest factors associated with newborn hypothermia.

The trend of neonatal mortality was showing good progress. The 2005 Ethiopian demographic, health survey (EDHS) with Neonatal mortality rate (NMR) of 39, 2011 EDHS with NMR of 37 to NMR of 29 in the 2016 EDHS. ${ }^{20}$ But the 2019 mini EDHS shows that the national NMR becomes 30 . This shows that further actions should be taken to improve neonatal survival in Ethiopia. ${ }^{21}$ The NMR of Oromiya regional sate was 37 , which is higher than the national NMR of $29 .{ }^{20}$
The ministry of health (Ethiopia) sets a standard routine care to prevent neonatal hypothermia in all health facilities in the country. The ministry recommends health professionals to warm the delivery room, organize newborn corner with adequate heat source before delivery and at birth: deliver the baby on mother's abdomen, dry the baby thoroughly immediately after birth and remove wet clothes, use cap to prevent significant heat loss through the scalp, keep the new-born in skin-to-skin contact with the mother, keep the new-born under preheated radiant warmer - if the need for resuscitation, cover weighing scales with a warm towel and initiate early breastfeeding. ${ }^{22}$ Hence, hypothermia among newborns is presumed to be an important contributor to neonatal morbidity and mortality; determinant factors of hypothermia in the region need further study. Therefore, this study is aimed to identify determinant factors of hypothermia among babies born in public health facilities in the West Shewa zone of Oromia regional state, Ethiopia.

\section{Methods}

\section{Study Area and Design}

A hospital-based unmatched case-control study design was employed among newborns at public hospitals in West Shewa zone of Oromia regional state, Ethiopia. West Shewa zone is located $114 \mathrm{~km}$ away from the country's capital city Addis Ababa. The data were collected from August 01 to December 30, 2019. There are eight hospitals in the study area providing delivery and other maternal and child health services.

\section{Source of Population and Study Population}

Five public hospitals were involved in the study, namely, Ambo general hospital, Ambo University referral hospital, Gedo Hospital, Guder Hospital and Ginde-beret Hospital. The source populations were all newborns and their mothers at public hospitals in West Shewa Zone during the study period. Newborns with serious medical problems and those who were transferred to the neonatal intensive care unit before the first hour were excluded. Also, Newborns with multiple births were excluded as the weight of the neonates and their respective temperatures differ. Cases were newly diagnosed neonates with hypothermia $\left(<36.5^{\circ} \mathrm{C}\right)$ measured at the first hour after delivery and Controls were neonates without hypothermia or $\geq 36.5^{\circ} \mathrm{C}$ at the first hour after delivery. Axillary 
temperature of newborns was measured by data collectors at the first hour after delivery for $3 \mathrm{~min}$ of duration by using a digital thermometer to identify cases and controls, which measures the surface temperature at the site of axilla according to the World health organization (WHO) recommendation. ${ }^{3}$

\section{Sample Size and Sampling Procedures}

The sample size of the study was calculated using Epi-info software version 7.1.1 with the following parameters for unmatched case-control study; significance 95\%, power $90 \%$, odds ratio 3.4 , the proportion of controls with exposure $11.4 \%$, and proportion of cases with exposure $30.7 \%$ from previous studies conducted in Tigray region, Ethiopia, ${ }^{18}$ case to control ratio $1: 1$ and we got 102 cases and 102 controls. After assuming a 10\% non-response rate, the total sample size yields 113 cases and 113 controls with an overall sample size of 226. The sample size was distributed proportionally to the five hospitals. All neonates who fulfill the case definition of neonates with hypothermia $\left(<36.5^{\circ} \mathrm{C}\right)$ measured at the first hour after deliveries were included in this study until the required sample size was obtained. Among neonates without hypothermia or $\geq 36.5^{\circ} \mathrm{C}$ at the first hour after delivery, the required numbers of controls were selected using a systematic random sampling technique. The sampling interval to select the controls was determined with a calculated $\mathrm{K}$-value (i.e. a $\mathrm{K}$-value was calculated by dividing the number of births in the selected hospitals, 3 months prior to data collection by the sample size required from each selected hospital). The first control was selected by lottery method from the babies born on the first day of the data collection. The rest of the study participants were selected consecutively using the K-value until the desired sample size was reached.

\section{Data Collection Tool, Quality Control and Measurements}

A structured, interviewer administered questionnaire, checklist and temperature measurements were used to collect data from both the cases and the controls. The interview questionnaire was prepared in English and translated into local language, fan-Oromo by language experts, and then translated back to English by a third person to check for consistency. The tool was adapted from previous literature in different parts of the world and modified according to the local context. The interview questionnaire addresses the information from the mothers regarding socio-demographic, past and current obstetric history. The checklist was used to collect secondary data from the study participants' medical card to collect information regarding the mode of delivery summary and immediate newborn cares given. A digital thermometer measurement was used to measure the neonate's temperature. The questionnaire template was coded by using open source software for Computer Assisted Personal Interviewing using census and survey processing system (CS-Pro) version 7.1 and deployed to Census and survey entry (CS-Entry) android application.

Five nurses from working in other facilities from the selected hospitals were recruited as data collectors and two assistant professors with a background of health professionals were hired as supervisors. In addition, the data collectors were trained for 2 days on the techniques of data collection and the purpose of the study for study participants before the start of data collection. A pre-test was done on $5 \%$ of the total study participant in Innchin hospital; a hospital found in the West Shewa Oromia region, which was not included in the actual study, and necessary adjustments were made.

\section{Data Processing and Analysis}

The data were collected and entered using the CS-Entry for the android version and exported to SPSS version 23 for analysis. Bivariate and multivariable logistic regressions were done to identify determinants of hypothermia. Those variables which were found to be significant with a p-value less than 0.05 during bivariate binary regression were included in the multivariate binary regression. Multicollinearity was diagnosed using the variance inflation factor. Finally, significant variables at $\mathrm{P}$-value $<0.05$ were considered as statistically significant in multivariable logistic regression and presented with an odd ratio and 95\% confidence interval (CI).

\section{Ethical Clearance}

Ethical clearance was obtained from the institutional review board (IRB) of Ambo University, West Shewa health bureau and respective hospitals. The ethics committee also approves to collect data from the newborns. The purpose of the study was explained to all study participants (mothers) about the information needed from the mother and her newborn and written consent was taken to collect data and communicate the findings through publication. They were also informed that all of their 
Table I Socio-Demographic Characteristics of Mothers in West Shewa Oromia, Ethiopia

\begin{tabular}{|c|c|c|c|c|}
\hline Characteristics & Cases Number (\%) & Control Number (\%) & Total Number (\%) & P-value \\
\hline \multicolumn{5}{|l|}{ Age category } \\
\hline Younger than 20 & $17(15.0)$ & $16(14.2)$ & $33(14.6)$ & 0.054 \\
\hline $20-29$ & $70(62.7)$ & $72(63.8)$ & $142(62.9)$ & \\
\hline $30-39$ & $21(18.6)$ & $22(19.5)$ & $43(19.0)$ & \\
\hline 40 and above & $5(3.7)$ & $3(2.6)$ & $8(3.5)$ & \\
\hline \multicolumn{5}{|l|}{ Mother education } \\
\hline No formal education & $35(31.0)$ & $42(37.2)$ & $77(34.1)$ & 0.299 \\
\hline Primary education (I-8) & $36(31.9)$ & $26(23.0)$ & $62(27.4)$ & \\
\hline Secondary education (9-12) & $21(18.6)$ & $17(15.0)$ & $38(16.8)$ & \\
\hline Collage and above & $21(18.6)$ & $28(24.8)$ & 49 (21.7) & \\
\hline \multicolumn{5}{|l|}{ Occupation mother } \\
\hline Government employee & $13(1 \mid .5)$ & $19(16.8)$ & $32(14.2)$ & 0.838 \\
\hline Private employee & $9(8.0)$ & $8(7.1)$ & $17(7.5)$ & \\
\hline Farmer & $35(31.0)$ & $34(30.1)$ & $69(30.5)$ & \\
\hline Merchant & $14(12.4)$ & $10(8.8)$ & $24(10.6)$ & \\
\hline House wife & $39(34.5)$ & $40(35.4)$ & $79(35.0)$ & \\
\hline Other & $3(2.7)$ & $2(1.8)$ & $5(2.2)$ & \\
\hline \multicolumn{5}{|l|}{ Residence } \\
\hline Rural & $62(54.9)$ & $61(54.0)$ & $123(54.4)$ & 0.894 \\
\hline Urban & $5 I(45.1)$ & $52(46.0)$ & $103(45.6)$ & \\
\hline \multicolumn{5}{|l|}{ Monthly income } \\
\hline Less than 1000 ETB & $47(4 \mid .6)$ & $34(30.1)$ & 81 (35.8) & 0.063 \\
\hline 1000-2500 ETB & $22(19.5)$ & $38(33.6)$ & $60(26.5)$ & \\
\hline 250I-5000 ETB & $31(27.4)$ & $25(22.1)$ & $56(24.8)$ & \\
\hline More than 5000 ETB & $13(11.5)$ & $16(14.2)$ & $29(12.8)$ & \\
\hline
\end{tabular}

responses are confidential and anonymous, and they have all the right not to be involved in the study or not to answer any of the questions. This study was conducted in accordance with the Declaration of Helsinki.

\section{Results}

\section{Socio-Demographic Characteristics of}

\section{Mothers}

In this study, a total of 113 hypothermic (cases) and 133 norm-thermic (control) were with their index mothers were included, making a response rate of $100 \%$. The mean $( \pm$ standard deviation) age of mothers was $26.7 \pm 5$ years' ranges from 17 to 43 years. The majority of the mothers were from the rural districts of West Shewa, Oromia region. The mean ( \pm standard deviation) of monthly income was $2775 \pm 3173$ Ethiopian Birr (ETB) (Table 1).

\section{Obstetric History of Mothers}

The majority of the mothers were multiparous (had more than one child) 201 (88.9\%); $102(90.3 \%)$ cases and 99 
Table 2 Obstetric History and Practice of Mothers in West Shewa Oromia, Ethiopia

\begin{tabular}{|c|c|c|c|c|}
\hline Characteristics & Cases Number (\%) & Control Number (\%) & Total Number (\%) & P-value \\
\hline \multicolumn{5}{|l|}{ Number of Children } \\
\hline Prim-parous & II (9.7) & $14(\mid 2.4)$ & $25(11.1)$ & 0.525 \\
\hline Multiparous & $102(90.3)$ & $99(87.6)$ & $201(88.9)$ & \\
\hline \multicolumn{5}{|l|}{ Birth interval } \\
\hline$\leq 2$ years & $64(56.6)$ & $56(49.6)$ & $120(53.1)$ & 0.286 \\
\hline$>2$ years & $49(43.4)$ & $57(50.4)$ & $106(46.9)$ & \\
\hline \multicolumn{5}{|l|}{ ANC } \\
\hline Yes & $99(87.6)$ & $101(89.4)$ & $200(88.5)$ & 0.677 \\
\hline No & $14(12.4)$ & $12(10.6)$ & $26(11.5)$ & \\
\hline \multicolumn{5}{|c|}{ History of obstetric complication } \\
\hline Yes & $6(5.3)$ & $17(I 5.0)$ & $23(13.3)$ & 0.472 \\
\hline No & $107(94.7)$ & $96(85.0)$ & $203(86.7)$ & \\
\hline \multicolumn{5}{|l|}{ Labor onset } \\
\hline Spontaneous & $100(88.5)$ & $98(86.7)$ & $198(87.6)$ & 0.686 \\
\hline Induced & $13(11.5)$ & $15(13.3)$ & $28(12.4)$ & \\
\hline \multicolumn{5}{|l|}{ Mode of delivery } \\
\hline SVD & $72(63.7)$ & $72(67.3)$ & $169(74.8)$ & 0.751 \\
\hline Assisted vaginal delivery & $27(23.9)$ & $23(20.4)$ & $8(20.7)$ & \\
\hline Cesarean section & $14(12.4)$ & $35(12.4)$ & $49(21.7)$ & \\
\hline
\end{tabular}

(87.6\%) of controls. Among the total of mothers, 200 (88.5\%) had ANC and 203 (86.7\%) had no any history of complication during pregnancy. Regarding labor and delivery process, $198(87.6 \%)$ of the mothers labor starts spontaneously and $169(74.8 \%)$ of the mothers delivered through spontaneous vaginal delivery (SVD) (Table 2).

\section{Neonate and Immediate Newborn Care-Related Characteristics}

Among the total of newborns in this study; 155 (68.6\%) were males and the majority of them were term babies 200 (88.5\%), normal birth weight 194 (85.8\%), had skin-to-skin contact with their mothers 193 (85.4\%) and 117 (82.4\%) were HIV negatives. Regarding the timing of breastfeeding initiated, $36(31.9 \%)$ from cases and $61(54.0 \%)$ of controls were breastfeed within 1 hour after delivery. A total of study participants 129 (57.1\%); 45 (38.9\%) cases and $51(45.1 \%)$ had APGAR scores above seven at 5 minutes (Table 3). The mean temperature of the cases was $35.1^{\circ} \mathrm{C}$ with a standard deviation (SD) of $1.1^{\circ} \mathrm{C}$ and the mean temperature of controls was $37.5^{\circ} \mathrm{C}$ with $\mathrm{SD} 0.6^{\circ} \mathrm{C}$. Hypothermia classified as mild hypothermia $\left(36.0-36.5^{\circ} \mathrm{C}\right)$, moderate hypothermia $\left(32.0-35.9^{\circ} \mathrm{C}\right)$ and severe hypothermia (less than $32^{\circ} \mathrm{C}$ ) according to the WHO classification. ${ }^{3}$ In this study, from the hypothermic babies, 37 (32.7\%) were mild hypothermia, $75(66.4 \%)$ were moderate hypothermia and only $1(0.9 \%)$ were under the classification of severe hypothermia.

\section{Determinants of Neonatal Hypothermia}

The independent predictors of hypothermia with a P-value less than 0.05 among neonates were breastfeeding, skin-toskin contact, gestational age, birth weight and respiratory distress. In the multivariable binary logistic regression analysis, only three variables had shown an overall 
Table 3 Neonate and Immediate Newborn Cares-Related Characteristics in West Shewa Oromia, Ethiopia

\begin{tabular}{|c|c|c|c|c|}
\hline Characteristics & Cases Number (\%) & Control Number (\%) & Total Number (\%) & P-value \\
\hline \multicolumn{5}{|l|}{ Sex } \\
\hline Male & $69(61.1)$ & $86(76.1)$ & $155(68.6)$ & 0.011 \\
\hline Female & $44(38.9)$ & $27(23.9)$ & 71 (3I.4) & \\
\hline \multicolumn{5}{|l|}{ Gestational age } \\
\hline$<37$ Weeks & $8(7.1)$ & $18(15.9)$ & $26(11.5)$ & 0.037 \\
\hline$\geq 37$ Weeks & $105(92.9)$ & $95(84.1)$ & $200(88.5)$ & \\
\hline \multicolumn{5}{|l|}{ Birth weight } \\
\hline Low birth weight & $22(19.5)$ & $10(8.8)$ & $32(14.2)$ & 0.022 \\
\hline Normal birth weight & $91(80.5)$ & $103(91.2)$ & $194(85.8)$ & \\
\hline \multicolumn{5}{|l|}{ Respiratory distress } \\
\hline Present & $62(54.9)$ & 44 (38.9) & $130(57.5)$ & 0.016 \\
\hline Absent & $51(45.1)$ & $69(61.1)$ & $96(42.5)$ & \\
\hline \multicolumn{5}{|l|}{ APGAR at $5 \mathrm{~min}$} \\
\hline$<7$ & $68(60.2)$ & $62(54.9)$ & $97(42.9)$ & 0.419 \\
\hline$\geq 7$ & $45(39.8)$ & $5 I(45.1)$ & $129(57.1)$ & \\
\hline \multicolumn{5}{|l|}{ Breastfeeding } \\
\hline Yes & $36(31.9)$ & $61(54.0)$ & $130(57.5)$ & 0.001 \\
\hline No & $77(68.1)$ & $52(46.0)$ & $96(42.5)$ & \\
\hline \multicolumn{5}{|l|}{ Skin-to-skin contact } \\
\hline Yes & $89(78.8)$ & $104(92.0)$ & $193(85.4)$ & 0.005 \\
\hline No & $24(21.2)$ & $9(8.0)$ & $33(14.6)$ & \\
\hline \multicolumn{5}{|l|}{ HIV status } \\
\hline Positive & $7(10.1)$ & $15(20.5)$ & $22(15.5)$ & 0.045 \\
\hline Negative & 62 (89.9) & $55(75.3)$ & II (82.4) & \\
\hline
\end{tabular}

significant effect on the risk of neonatal hypothermia at the $5 \%$ level of significance. Neonates who had not started breastfeeding within 1 hour after delivery are about 2.2 times at risk of hypothermia than their counterparts $[\mathrm{AOR}=2.2,95 \% \mathrm{CI}(1.3,4.1)]$. Neonates who had not skin-to-skin contact with their mothers are about three times at higher risk to develop hypothermia than those neonates who had skin-to-skin contact with their mothers $[\mathrm{AOR}=2.8,95 \% \mathrm{CI}(1.3,6.6)]$. Finally, neonates with birth weight less than $2500 \mathrm{~g}$ are 2.6 times at higher risk of hypothermia than their counterparts $[\mathrm{AOR}=2.6,95 \% \mathrm{CI}$ $(1.3,5.2)]$ (Table 4).

\section{Discussion}

In this study, we have tried to identify determinants of neonatal hypothermia and we also found similar risk factors previously indicated by different scholars. Breastfeeding initiation within 1 hour, skin-to-skin contact, and low birth weight are found to be one of the determinant factors of hypothermia. Newborns that did not start breastfeeding within 1 hour are about two times more likely to develop hypothermia. This is similar to studies conducted in, Nepal, ${ }^{8} \mathrm{Zambia}^{23}$ and studies from Ethiopia' Addis Ababa, ${ }^{9}$ Tigray region, ${ }^{18}$ Amhara region $^{24}$ and, Gondar, Northern Ethiopia. ${ }^{11}$ This may be due to 
Table 4 Determinates of Hypothermia Among Neonates at NICU in West Shewa Oromia, Ethiopia

\begin{tabular}{|c|c|c|c|c|}
\hline Characteristics & Cases Number (\%) & Control Number (\%) & COR (95\% Cl) & AOR $(95 \% \mathrm{Cl})$ \\
\hline \multicolumn{5}{|c|}{ Breastfeeding with in I $\mathrm{hr}$} \\
\hline Yes & $36(31.9)$ & $61(54.0)$ & 1 & 1 \\
\hline No & $77(68.1)$ & $52(46.0)$ & $2.3(1.3,4.2)$ & $2.2(1.3,4.1)^{*}$ \\
\hline \multicolumn{5}{|c|}{ Skin-to-skin contact } \\
\hline Yes & $89(78.8)$ & $104(92.0)$ & 1 & 1 \\
\hline No & $24(21.2)$ & $9(8.0)$ & $3.1(1.3,6.9)$ & $2.8(1.3,6.6)^{*}$ \\
\hline \multicolumn{5}{|l|}{ Gestational Age } \\
\hline$<37$ Weeks & $8(7.1)$ & $18(15.9)$ & 1 & 1 \\
\hline$\geq 37$ Weeks & $105(92.9)$ & $95(84.1)$ & $2.4(1.1,5.8)$ & 2.I $(0.8,5.3)$ \\
\hline \multicolumn{5}{|l|}{ Birth weight } \\
\hline$<2500 \mathrm{~g}$ & $22(19.5)$ & $10(8.8)$ & $2.4(1.2,5.9)$ & $2.6(1.3,5.2)^{*}$ \\
\hline$\geq 2500 \mathrm{~g}$ & $91(80.5)$ & 103 (9I.2) & & I \\
\hline \multicolumn{5}{|c|}{ Respiratory distress } \\
\hline Present & $62(54.9)$ & $44(38.9)$ & $1.9(1.1,3.2)$ & $1.5(0.9,2.8)$ \\
\hline Absent & $51(45.1)$ & $69(6 I .1)$ & I & I \\
\hline
\end{tabular}

Note: *P-value less than 0.05 .

early initiation of breastfeeding facilitated skin-to-skin contact immediately, prevent exposing the baby to the environment, increase follow up care to mothers for their child and breast milk is the source of energy or calories to produce heat for thermoregulation and they have no adequate adipose tissue for glucose breakdown which results in hypothermia.

Skin-to-skin contact had a significant association with neonatal hypothermia in this study. This is found to be similar to, the risk of developing hypothermia among newborns who do not have skin-to-skin contacts is from 2 to 5 times than their counterparts according to studies conducted in Iran, ${ }^{25}$ Zambia $^{22}$ and, studies from Ethiopia; Addis Ababa ${ }^{9}$ Gondar, ${ }^{11}$ Harar city, Eastern Ethiopia, ${ }^{10}$ Southern Ethiopia, ${ }^{13}$ and Tigray. ${ }^{18}$ The possible reason could be in the temperature of the fetus in the uterus is consistent with the maternal temperature; Newborns who had skin-to-skin contact immediately after delivery with their mother gain heat through conduction which is consistent with their temperature in the womb during exposure of the newborn to the extrauterine environment. Skin-to-skin contact is more effective than incubator care for re-warming the newborn. It may also be due to the maternal chest and abdominal movement that stimulates the newborn for enhanced breathing which improves heat generation through oxidative phosphorylation. The WHO and American pediatric association recommends that newborns without complications should be kept in skin-to-skin contact with their mothers during the first hour after birth to prevent hypothermia and promote breastfeeding. ${ }^{3,5,15}$

This study also found out that low birth weight newborns are 2.6 times at higher risk of developing hypothermia than normal Wight babies. This is also supported by the findings from studies conducted in Lebanon ${ }^{15}$ Nepal 8, Nigeria, ${ }^{26}$ and studies from Ethiopia; Tigray, ${ }^{18}$ and Gondar. ${ }^{11}$ It is also a consistent finding with a global hypothermia systematic review. ${ }^{6}$ The main reason that low birth weights are at greater risk of hypothermia is due to their higher surface area to weight, their decreased subcutaneous fat with its less isolative capacity, and less developed stores of brown adipose tissue. ${ }^{5}$

\section{Limitation of the Study}

Finally, we would like to inform our readers that this study was conducted among babies born in public hospitals; therefore, the result does not represent the general community as the samples were specific to women delivered in 
public health facilities. Furthermore, due to Health care access bias: as the women in health facilities are more likely to have better information than those who do not receive health care, our study may miss some determinant factors that may affect the occurrence of the outcome variable. There is also a chance of Mis-classification bias: as the temperature was measured once and the cut point was small, this could affect the classification and the overall result. Therefore, we recommend our readers to consider these limitations while reading, interpreting the findings and also while considering to cite this study.

\section{Conclusion and Recommendations}

The finding of this study showed that initiation of breastfeeding within 1 hour, newborn skin-to-skin contact with their mother, and low birth weight are found to be determinant factors of neonatal hypothermia among newborns in public health hospitals of West Shewa, Oromia regional state. Therefore, this study strengthens this evidence regarding the determinants of hypothermia and the situations in the study are is not different. Following the recommendations of WHO and national guidelines, to initiate breastfeeding immediately and skin-to-skin contact is crucial and immediate newborn. Low birth weight babies are at risk of developing hypothermia than other babies. Therefore, due attention should be given for low birth weights and other hypothermic prevention plans and cares should be given to those newborns.

\section{Abbreviations}

AOR, adjusted odds ratio; APGAR, Appearance, Pulse, Grimace, Activity, and Respiration; COR, crude odds ratio; $\mathrm{CI}$, confidence interval; CSPRO, census and survey processing system; CS-Entry, census and survey entry; EDHS, Ethiopian Demographic Health Survey; ETB, Ethiopian birr; NMR, neonatal mortality rate; SD, standard deviation; VIF, variance inflation factors; WHO, World Health Organization.

\section{Data Sharing Statement}

Full data for this research are available through the corresponding author upon request.

\section{Ethics Approval and Consent for Publication}

Ethical clearance was obtained from the institutional review board (IRB) of Ambo University West Shewa health bureau and respective hospitals. The ethics committee also approves to collect data from the newborns. The purpose of the study was explained to all study participants (mothers) about the information needed from the mother and her newborn, and written consent was taken to collect data and communicate the findings through publication. They were also informed that all of their responses are confidential and anonymous, and they have all the right not to be involved in the study or not to answer any of the questions. This study was conducted in accordance with the Declaration of Helsinki.

\section{Acknowledgments}

We would like to express deepest heartfelt thanks to Ambo University for allowing the conduct of this study and funding. We would like to thank the West Shewa town Health Bureau and the hospitals involved in the study. Special thanks also goes to study participants, data collectors and supervisors.

\section{Author Contributions}

All authors (BS, DB, KS and GA) made a significant contribution to the conception, study design, execution, acquisition of data, analysis and interpretation; gave final approval of the version to be published; have agreed on the journal to which the article has been submitted; and agree to be accountable for all aspects of the work.

\section{Funding}

Ambo University.

\section{Disclosure}

The authors declare that they have no competing interests.

\section{References}

1. UN. The Sustainable Development Goals Report 2019. 2019.

2. UNICEF. UNICEF GLOBAL DATABASES:Regional and Global Infant Deaths. 2019. Accessed 19 September 2019.

3. World Health Organization M, Newborn Health/Safe M. Thermal Protection of the Newborn: A Practical Guide. Geneva: World Health Organization; 1997.

4. Mullany LC. Neonatal hypothermia in low-resource settings. Semin Perinatol. 2010;34:426-433.

5. NHS. Management of Neonatal Hypothermia. 2019.

6. Lunze K, Bloom DE, Jamison DT, Hamer DH. The global burden of neonatal hypothermia: systematic review of a major challenge for newborn survival. BMC Med. 2013;11(24):1.

7. Sodemann M, Nielsen J, Veirum J, et al. Hypothermia of newborns is associated with excess mortality in the first 2 months of life in Guinea-Bissau, West Africa. Trop Med Int Health. 2008;13 (8):980-986.

8. Mullany LC, Joanne Katz SK, Khatry SC, LeClerq GL, Darmstadt JM. Risk of mortality associated with neonatal hypothermia in Southern Nepal. Arch Pediatr Adolesc Med. 2010;164:7. 
9. Demissie BW 1, Abera BB 2, Chichiabellu TY 3, Astawesegn FH Neonatal hypothermia and associated factors among neonates admitted to neonatal intensive care unit of public hospitals in Addis Ababa, Ethiopia. BMC Pediatr. 2018;18(263):1-10.

10. Bayih WA, Assefa N, Dheresa M, Minuye B, Demis S. Neonatal hypothermia and associated factors within six hours of delivery in eastern part of Ethiopia: a cross-sectional study. BMC Pediatr. 2019;19(252):1-10.

11. Seyum T, Ebrahim E. Proportion of neonatal hypothermia and associated factors among new-borns at Gondar University Teaching and referral hospital, Northwest Ethiopia: a Hospital Based Cross Sectional Study. Gen Med. 2015;3(4).

12. Beletew BA, Kasie AM, Mwk R. Neonatal hypothermia and its associated factors in East Africa: a systematic review and meta-analysis. Res Square. 2020.

13. Ukke GG, Diriba K. Prevalence and factors associated with neonatal hypothermia on admission to neonatal intensive care units in Southwest Ethiopia - a cross-sectional study. PLoS One. 2019;14 (6): 0218020.

14. McCall EMAF, Halliday HL, Vohra S, Johnston L. Interventions to prevent hypothermia at birth in preterm and/or low birthweight infants (review). Cochrane library. 2018.

15. Andrews C, Whatley C, Smith M, Brayton EC, Simone S, Holmes AV. Quality-improvement effort to reduce hypothermia among high-risk infants on a mother-infant unit. Pediatrics. 2018;141(3).

16. Soares T, Pedroza GA, Breigeiron MK, Mlc C. Prevalence of hypothermia in the first hour of life of premature infants weighing $\leq 1500$ g. Rev Gaúcha Enferm. 2020;41.

17. Zayeri F, Kazemnejad A, Ganjali M, Babaei G, Nayeri F. Incidence and risk factors of neonatal hypothermia at referral hospitals in Tehran, Islamic Republic of Iran. East Mediterr Health J. 2007;13 (6):1308-1318.
18. Tasew H, Gebrekristos K, Kidanu K, Mariye T, Teklay G. Determinants of hypothermia on neonates admitted to the intensive care unit of public hospitals of Central Zone, Tigray, Ethiopia 2017: unmatched case-control study. BMC Res Notes. 2018;11(576):1-6.

19. Nyandiko WM, Kiptoon P, Lubuya FA. Neonatal hypothermia and adherence to World Health Organisation thermal care guidelines among newborns at moi teaching and referral hospital, Kenya. medRxiv. 2020.

20. (CSA) CSA, ICF. Ethiopia Demographic and Health Survey. Addis Ababa, Ethiopia, and Rockville, Maryland, USA: CSA and ICF; 2016.

21. and EPHIEE, ICF. Ethiopia Mini Demographic and Health Survey 2019: Key Indicators. Rockville, Maryland, USA: EPHI and ICF; 2019.

22. Ethiopian Federal Ministry of Health. Neonatal Intensive Care Unit (NICU) Training Management Protocol. 2014.

23. Lunze K, Yeboah-Antwi K, Marsh DR, et al. Prevention and management of neonatal hypothermia in Rural Zambia. PLoS One. 2014;9 (4):e92006.

24. Nebiyu S, Berhanu M, Liyew B. Magnitude and factors associated with neonatal hypothermia among neonates admitted in neonatal intensive care units: multicenter cross-sectional study. J Neonatal Nurs. 2020.

25. Delavar MA, Akbarianrad Z, Mansouri MM, Yahyapour M. Neonatal hypothermia and associated risk factors at baby friendly Hospital in Babol, Iran. Ann Med Health Sci Res. 2014;4(2):99-103.

26. Ogunlesi TA, Ogunfowora OB, Ogundeyi MM. Prevalence and risk factors for hypothermia on admission in Nigerian babies $<72 \mathrm{~h}$ of age. J Perinat Med. 2009;37(2):180-184
Research and Reports in Neonatology

\section{Publish your work in this journal}

Research and Reports in Neonatology is an international, peerreviewed, open access journal publishing original research, reports, editorials, reviews and commentaries on neonatal health. The manuscript management system is completely online and includes a very quick and fair peer-review system. Visit http://www.dovepress. com/testimonials.php to read real quotes from published authors. 